\title{
УДК 551 \\ ИНФОРМАТИВНОСТЬ ГЕОМЕТРИЧЕСКИХ АТРИБУТОВ ДЛЯ ПРОГНОЗИРОВАНИЯ ТРЕЩИНОВАТОСТИ КОЛЛЕКТОРОВ НА ПРИМЕРЕ МЕСТОРОЖДЕНИЯ УГЛЕВОДОРОДОВ ТОМСКОЙ ОБЛАСТИ
}

\author{
Орехов Александр Николаевич',
}

orekhovan@mail.tomsknet.ru

\author{
Амани Мангуа Марк Марсьяль', \\ mangouam@yahoo.fr \\ 1 Национальный исследовательский Томский политехнический университет, \\ Россия, 635050, г. Томск, пр. Ленина, 30.
} В последние годы, в связи систощением традиционных коллекторов углеводородов, значительно возрос интерес к коллекторам,
проницаемость которых обусловлена главным образом степенью их трещиноватости. Перспективы картирования зон трещино-
ватости связывают с сейсморазведкой. По существу, она является единственным наземным геофизическим методом, который
позволяет получить детальное трехмерное изображение геологической среды. Однако возможности сейсморазведки ограниче-
ны ее разрешающей способностью и строением интервалов коллекторов. Исходя из результатов выполненного нами ранее срав-
нительного анализа новейших методик и технологических приемов изучения трещинно-кавернозных коллекторов, были проте-
стированы основные методы анализа сейсмических данных в той последовательности, в которой они излагаются в обзорах. Они
ранжированы по широте использования и доказанной эффективности. По убывающей эффективности, методы изучения трещи-
новатости располагаются следующим образом: 1. Азимутальный анализ анизотропии сполучением эффективной модели азиму-
тальной анизотропии; 2. Анализ геометрических атрибутов; З. Специальные технологии миграционных преобразований (ду-
плексная миграция и др.); 4. Выделение из сейсмической записи поля рассеянных волн. Так как проведенная на участке работ
сейсморазведка является стандартной (не широкозимутальной, не мультиазимутальной, не многоволновой), то для исследо-
вания трещиноватости из списка вышеперечисленных методов нам были доступны только приёмы анализа геометрических ат-
рибутов. Необходимо отметить, что в этом случае прогноз трещиноватости мог быть ограничен выделением зон трещиновато-
сти (качественный анализ).

Цель: изучение возможностей атрибутного анализа сейсмических данных для прогноза выделения тектонических нарушения и зон повышения трещин.

Объекты: породы со сложным строением пустотного пространства интенсивной кавернозности и трещиноватости, за счет которых образовались тектонические дислокации в осадочном чехле.

Методология. Был рассчитан ряд объемных сейсмических атрибутов, таких как атрибуты когерентности (дисперсии) и кривизны (и ее разные варианты), хаоса. Полученные результаты были визуализированы в программном интерфейсе Petrel囚 компании Schlumberger с помощью имеющихся 3D МОГТ сейсмических данных для исследования потенциальных структурных и стратиграфических контролей и выделения зон с интенсивностью развития трещин в пределах исследуемой области. Аналогичным образом для горизонтов были рассчитаны поверхностные атрибуты с целью создания карт атрибутов и получения полного понимания строения целевых объектов и признаков для выделения зон интенсивного развития трещин.

Результаты. Проведен анализ геометрических атрибутов для выделения зон повышения трещин, также была рассмотрена калибровка сейсмических атрибутов по данным скважин (керна).

\section{Ключевые слова:}

Коллекторы каверно-порового типа, трещинный тип, трещинно-порово-каверновый тип, сейсмические атрибуты, геометрические атрибуты, когерентность, кривизна, хаос, Ant-Tracking.

\section{Введение}

Существует несколько основных вариантов применения сейсмических атрибутов для решения геологических задач. В настоящее время они используются:

1) для прослеживания тектонических нарушений, корреляции сейсмических горизонтов и др., то есть классических задач сейсморазведки;

2) площадной интерполяции и экстраполяции ФЕС (фильтрационно-ёмкостных свойств) пород по сейсмическим данным при редкой сети скважин, а значит и скважинных наблюдений. Для прогноза ФЕС используются методики на основе применения нейронных сетей и геостатистики (в том числе многомерной);
3) определения закономерностей и характера изменения фильтрационно-емкостных свойств и литологии изучаемых разрезов на основе восстановления истории развития резервуара (как диагенетической, так и аккумулятивной и тектонической);

4) прогнозирования нефтегазоносности на поисковом этапе [1-4].

Классификация сейслических атрибутов. Физический смысл и геологическое применение. Многие авторы занимались классификацией сейсмических атрибутов. Например, М. Танер представил всеобъемлющую классификацию атрибутов, разделив их на две категории: геометрическую и физическую, в зависимости от их отношения к геологии. Геометрические атрибуты обладают способно- 
стью улучшать видимость геометрических характеристик сейсмических событий и чувствительны к латеральным изменениям свойства пласта, азимута, непрерывности, подобия, кривизны и энергии. Они используются для выявления тектонических нарушений или структурной и стратиграфической интерпретации $[5,6]$. Однако физические атрибуты усиливают физические параметры поверхности, относящиеся к литологии и стратиграфии для литологической классификации и характеристики пласта. Они включают амплитуду, фазу и частоту сейсмических событий.

Геолетрические атрибуты преимущественно направлены на анализ геометрии сейсмического горизонта, что является прямым признаком наличия трещиноватости. К геометрическим атрибутам относится большая часть всех применяющихся на практике методов. Среди геометрических атрибутов, перспективных на обнаружение латеральных неоднородностей, таких как зоны выклинивания, погребенные русла, разрывные нарушения, зоны повышенной трещиноватости в первую очередь следует назвать: когерентность, кривизна и хаос.

Геометрические атрибуты считаются информативными для выявления трещиноватых зон различного генезиса (как трещин скола, так и трещин отрыва). Они реагируют именно на повышение трещиноватости среды вне зависимости от природы её возникновения.

Краткая сейслогеологическая характеристи$\kappa a$. Изучаемое месторождение территориально находится в Александровском районе Томской области. Территория месторождения по географическому положению расположена в юго-восточной части Западно-Сибирской низменности и представляет собой плоскую заболоченную, терассированную аккумулятивную равнину, современные формы рельефа на которой образовались в результате экзогенных процессов (и проявления новейших тектонических эпигенетических движений).

В геологическом строении района работ принимают участие образования палеозойского складчатого фундамента и осадочные отложения мезо-кайнозойского платформенного чехла.

Согласно «Тектонической карте фундамента Западно-Сибирской плиты» (В.С. Сурков, О.Г. Жееро, 1981 г.), район исследования расположен в зоне сочленения северо-западных частей НазиноСенькинского антиклинория и Айгольского синклинория. Ядро антиклинория сложено интенсивно дислоцированными, метаморфизованными, предположительно салаирскими и каледонскими складчатыми комплексами. Осложняющие его синклинории представлены средне-верхнедевонскими карбонатно-терригенными толщами. С северо-запада Назино-Сенькинский антиклинорий и Айгольский синклинорий ограничены Колтогорско-Уренгойским грабен-рифтом; на юго-востоке их сечет Усть-Тымский грабен-рифт. Поверхность фундамента покрыта сетью оперяющих грабен- рифтов, протягивающихся с юго-запада на северовосток. Современные исследователи считают, что в строении грабен-рифтов принимают участие два структурно-формационных комплекса: собственно рифтовый, представленный интрузивными базитовыми образованиями, и грабеновый, сложенный преимущественно вулканогенно-осадочными породами. Для структурного плана мезозойско-кайнозойского чехла свойственна высокая степень унаследованности от рельефа эрозионно-тектонической поверхности фундамента. В соответствии с «Тектонической картой юрского структурного яруса осадочного чехла западных районов Томской области» (ред. А.Э. Конторович, 2001 г.) район отчетных исследований находится на западном склоне Александровского свода - структуры I порядка.

В нефтегазоносном отношении территория исследований относится к Александровскому нефтегазоносному району Васюганской нефтегазоносной области. Нефтегазоперспективность района связана с породами широкого стратиграфического диапазона, включающего в себя: верхнюю часть палеозойского фундамента и зону контакта отложений осадочного чехла с доюрскими образованиями (НГГЗК), нижнесреднеюрские отложения тюменской свиты, верхнеюрские отложения васюганской свиты, меловые отложения.

Когерентность - это атрибут, который позволяет выделить несоответствие сигнала по латерали и указывает на неоднородности сейсмического поля, обусловленные влиянием $30 н$ разломов, трещин и разрывных нарушений. Понятие регулярности волны и когерентности в некоторых источниках тесно связано. Определим понятие низкой когерентности как нарушение условия регулярности волны, т. е. когда форма (частота, коэффициент затухания или фаза) волны «быстро» меняется в пространстве.

Авторы представили «куб когерентности», сейсмический атрибут для отображения несоответствий в сейсмических трассах [7]. Они отметили, что поверхности разломов четко разделяются с соседними данными как визуально, так и численно, позволяя автоматическое пикирование с существующим автоматическим прослеживанием горизонтов. Данный атрибут начали использовать для предсказания разрывных нарушений и зон трещиноватости с тех пор, как продемонстрирована корреляция значений когерентности с разрывными нарушениями. Также авторы показали методику извлечения разломов из сейсмического куба, выполнив определение линейных особенностей по поперечным срезам куба когерентности [8].

Результаты анализа атрибута, приведённого на рис. 1, показывают, что наблюдается высокая дифференциация атрибута в продуктивном интервале трещиноватых пород. Хорошо выделяются линейные зоны повышенных значений атрибута, пространственно совпадающие с тектоническими нарушениями. Следовательно, повышенные значе- 


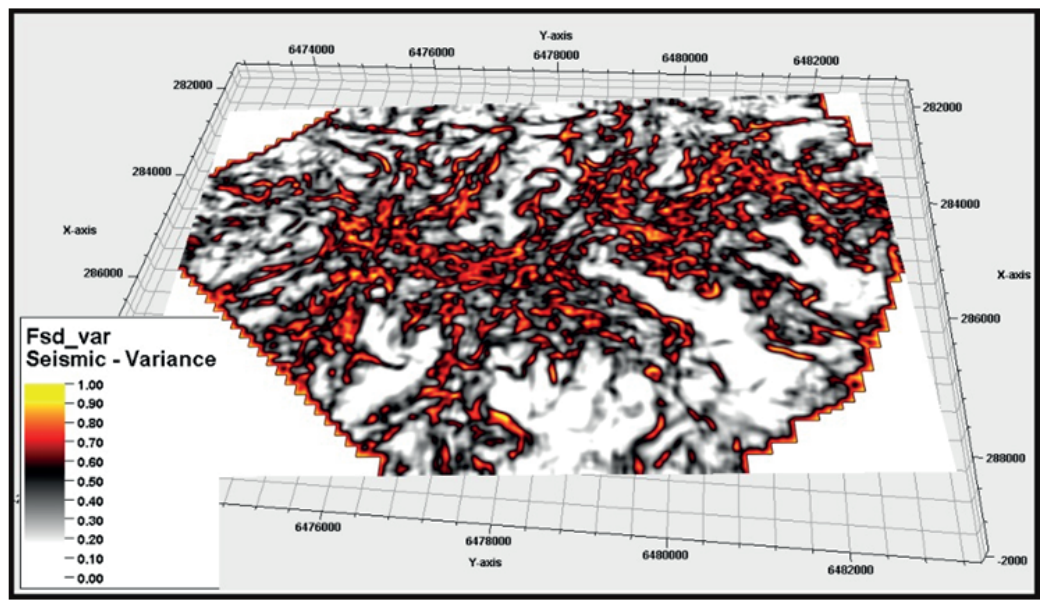

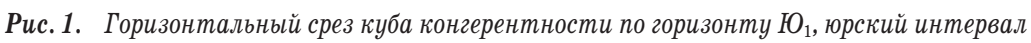

Fig. 1. Slice of the coherency (Variance) cube along the horizon $U_{1}$, Jurassic interval

ния когерентности могут быть признаком трещиноватых зон.

Объелная кривизна является мерой структурной деформации. Она анализирует форму сейсмического горизонта и показывает, насколько он изогнут в некоторой точке. Атрибуты кривизны начали активно использоваться для предсказания малоамплитудных разрывных нарушений и зон трещиноватости с тех пор, как была продемонстрирована корреляция значений кривизны с разрывными нарушениями [9]. Поскольку объемная кривизна пластов фокусируется на изменениях скорее формы, чем амплитуд, она меньше подвержена влиянию изменений поля сейсмической амплитуды, обусловленного изменчивостью флюида и литологии, и, в большей степени, фокусируется на изменчивости, обусловленной нарушениями и складчатостью. По мнению авторов работы [10], кривизна - хорошая мера палеодеформаций, приводящих к растрескиванию пород. Данный атрибут позволяет не только картировать трещиноватые зоны, но и судить о плотности трещин. Связь кривизны с плотностью трещин базируется на следующих трех предположениях: порода хрупкая и поэтому подвержена трещинообразованию; рост кривизны предполагает рост напряжения; рост напряжения предполагает рост плотности трещин. Разработка основ вычисления кривизны по сейсмическим данным выполнена в работе [11]. Методика предполагает вычисление искомых параметров только вдоль отражающих горизонтов. Несмотря на ряд практических положительных примеров использования так называемой погоризонтной кривизны, она содержит ряд недостатков [11]. Многими авторами $[6,11]$ было показано, что различные меры кривизны (кривизна азилут, среднял кривизна, лаксилальная кривизна $K_{\text {max }}$, инимальная кривизна $K_{\text {min, }}$ Гауссова кривизна и т. д.) имеют высокую корреляцию с разрывными нарушениями, но информативными для картирования тектонической нарушенности являются наибольшие положительная и отрицательная кривизны.

Xaoc («Chaos») - это гибридный атрибут [12], который используется для обнаружения хаотических зон пласта среди организованных событий. Хаотические зоны определяются как районы с высоким поперечным слоем непрерывности и с произвольными переменными тектоническими нарушениями. Зоны изменчивости атрибута скорее всего отражают зоны дробления, с которыми могут быть связаны трещиноватые коллектора.

Атрибут отображает «хаотичность» локального сейсмического сигнала. Эта хаотичность означает, насколько последовательна оценка направления, основанная на методе главных компонентов. При этом зоны с недостаточной последовательностью в оценке соответствуют зонам с хаотичным сигналом волн. Таким образом, этот атрибут является подходящим для выявления хаотичной структуры среды.

Области с недостаточной последовательностью соответствуют зонам с хаотичным сигналом волн и могут быть связаны с геологическими особенностями; например, разломы/неоднородности, каналы и т. д. Важными особенностями атрибута «ChaOS» является направление и амплитудная неизменность. Таким образом, на выходе будет одинаковый результат как при больших, так и при малых значениях амплитуд.

Колплексирование геолетрических атрибутов. Применение одного сейсмического атрибута может привести к недостаточно достоверным результатам. Поэтому оптимальным можно считать комплексирование нескольких атрибутов для повышения достоверности и детальности оценки зон с интенсивностью развития трещин.

Наиболее положительная кривизна $\left(K_{+}\right)$и наибольшая отрицательная кривизна $\left(K_{-}\right)$отображают почти все напряжения, содержащиеся на поверхности и связанные с разломами, имеющими 
полигональный вид. Величина напряжения также сохраняется, что позволяет лучше распознавать зоны развития трещин и их направления. Однако информация о форме не сохраняется с этим атрибутом.

На рис. 2 показан горизонтальный срез кубов наибольшей положительной кривизны $\left(K_{+}\right)$и когерентности по горизонту $Ю_{1}$. Можно обратить внимание на корреляцию наибольшей отрицательной кривизны и аномалий высокой когерентности с зоны повышения трещиноватости. Разломы и зоны повышенной трещиноватости по этим атрибутам хорошо согласуются с поведением вышеназванных атрибутов. Также можно обратить внимание на то, что особенности атрибута «Когерентность» позволяют значительно более уверенно выделять зоны с повышенной трещиноватостью.

С целью получения дополнительной информации также, совместно с когерентностью, был рассчитан $K_{\min }$ и $K_{\max }$ (максимальная кривизна, минимальная кривизна).

Максилальная кривизна складывается из бесконечного числа нормальных кривизн, проходящих через определенную точку на поверхности. Существует одна кривая, определяющая наибольшую абсолютную кривизну.

Минилальная кривизна - кривая, перпендикулярная максимальной кривизне. Визуально этот атрибут может казаться «зашумлённым», но иногда он может быть диагностическим при определении областей разломов и используется для вычисления других атрибутов кривизны.

На рис. 3 приведены результаты сопоставления горизонтальных срезов кубов кривизны и хаоса. Очевидно, что существует сильная корреляция аномалий повышенных значений хаоса с зоной повышения трещиноватости.

Приведённые выше материалы показывают, что именно гибридный атрибут «Chaos» является наиболее информативным для выделения зон повышенной трещиноватости.

Аномально высокие пластовые давления (АВПД) широко распространены на месторождениях углеводородов с трещинно-кавернозными коллекторами. Наличие АВПД увеличивает естественную энергетику пластов, улучшает их коллекторские свойства. С другой стороны, неучет АВПД может привести к аварийным ситуациям при бурении [13-15]. Для снижения геологического риска при бурении нами была также рассчитана кривизна (Curvature dip) в направлении максимального падения. Она определяет кривизну падения. Таким образом, кривизна является мерой скорости изменения угла наклона в направлении максимального падения. Dip - это первый атрибут, основанный на производной, и используется он в основном для обнаружения границ и зон контактов геологических тел, которые связаны с асимметричными (разломами) и симметричными (выступы/впадины) поверхностными характеристиками.

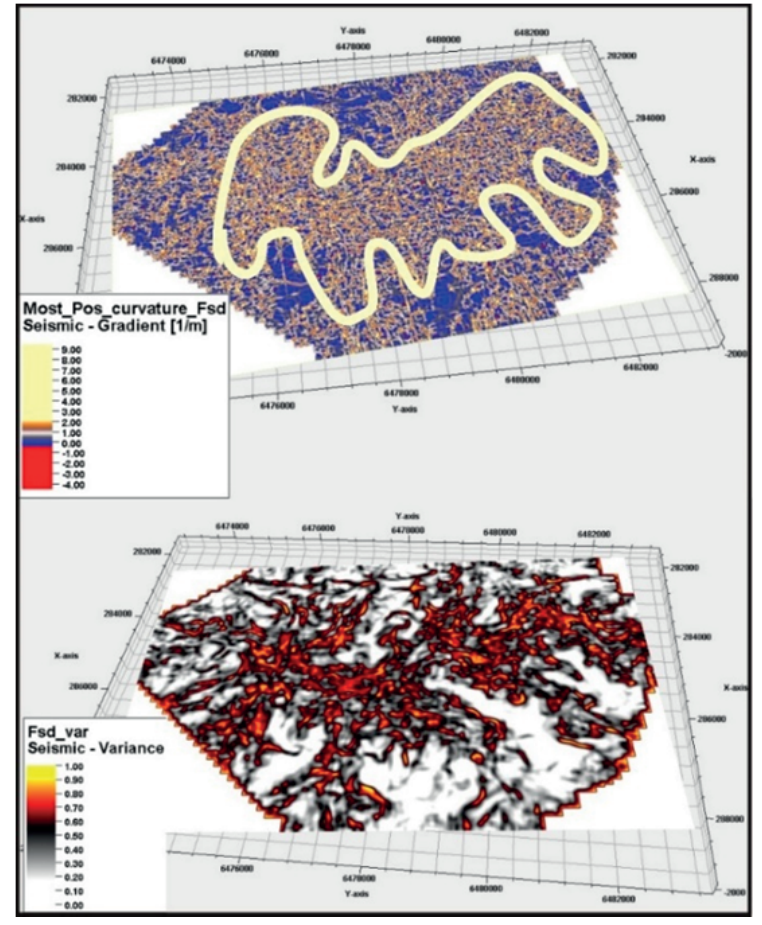

Pис.2. Горизонтальный срез кубов наиболее положительной кривизны и когерентности по горизонту Ю $Ю_{1}$, юрский интервал

Fig. 2. Slice of most positive curvature cube and coherency along the horizon $U_{1}$, Jurassic interval

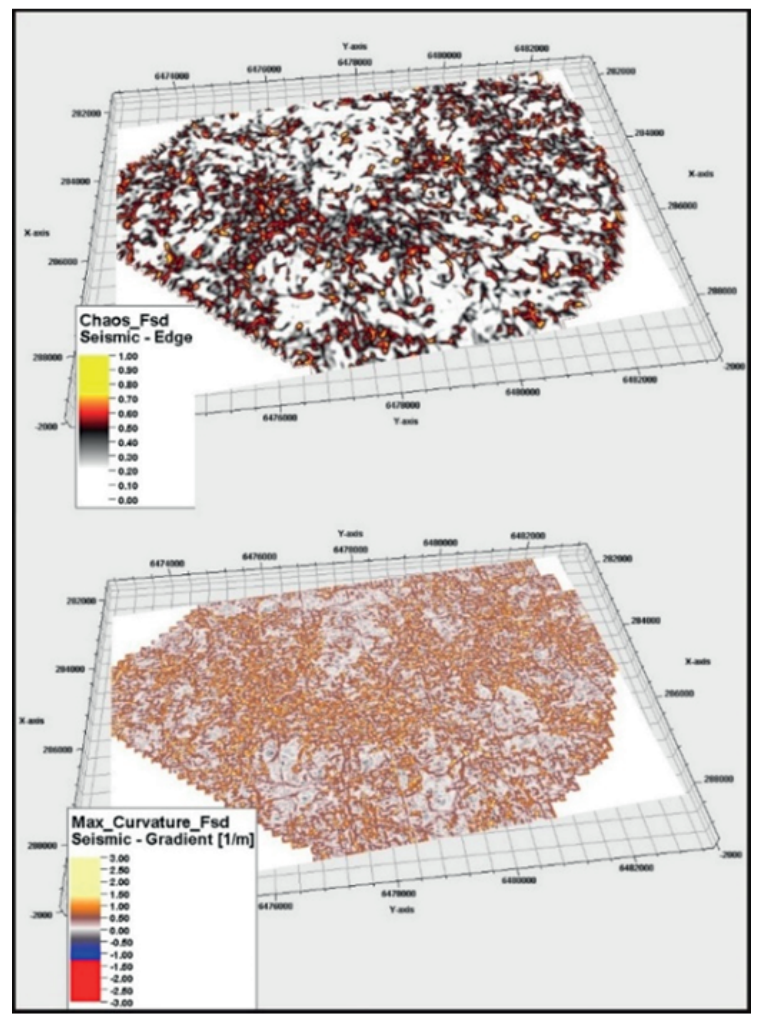

Рис. 3. Горизонтальный срез кубов хаос и максимальной кривизны по горизонту $Ю_{1}$, юрский интервал

Fig. 3. Slice of the chaos and maximum curvature cube along the horizon $U_{1}$, Jurassic interval 
Кроме того, нами был рассчитан индекс формы - s, который использует комбинацию атрибутов максимальной и минимальной кривизны и описывает локальную морфологию поверхности, не зависящей от масштаба. Поскольку на этот атрибут не влияет абсолютная величина кривизны (за исключением плоских поверхностей), могут быть с большей достоверностью выделены маломощные разломы и зоны трещиноватости, а также оценены другие поверхностные характеристики.

Трещиноватость часто выше у оси сгиба пород $[16,17]$ и, следовательно, связана с напряжением аномалий кривизны. Трещины часто сильнее вблизи оси складок, иногда они параллельны, часто под углом, и, значит, пространственно приурочены к напряжению аномалий кривизны. Поэтому комплексирование атрибутов кривизны Dip и s является надежным инструментом для выделения зоны повышения напряжения.

Таким образом, нами опробованы несколько известных атрибутов для интерпретации и картирования зоны повышения трещин в стандартные сейсморазведки. По геометрическим атрибутам нами получены четыре варианта прогнозных карт строения трещиноватых коллекторов

Для наиболее полного понимания распространения трещиноватости в исследуемой породе недостаточно только сейсмических данных. Также необходимо комплексирование сейсморазведки с другими данными, содержащими информацию о трещинах [18].

\section{Современные технологии компании Шлюмберже}

На сегодняшний день наиболее современной является технология картирования направления трещин с помощью алгоритма Ant-tracking, использующего скважинные данные. "Ant Tracking» Schlumberger [19-21] - это алгоритм обработки изображений, который улучшает видимость разломов и других плоских поверхностей. Он связан с применением когерентности, связности и других атрибутов. Алгоритм «Ant Tracking»- это итерационный метод, который объединяет выровненные, но не пересекающиеся мелкие плоские объекты на более крупные непрерывные поверхности. Можно контролировать ориентацию отслеживаемых поверхностей. Таким образом, его можно использовать в качестве фильтра. Алгоритм позволяет: усилить проявленность разломов с помощью атрибутов; генерировать атрибуты, чувствительные к трещинам (например, когерентность, кривизна, хаос); оценить ориентацию разрывов по данным из других источников и результатов скважинных измерений; выделить нарушения, которые попадают в определенный пространственный диапазон.

Типовой разрез месторождения, которое мы используем как тестовое, составлен по данным, полученным в процессе бурения, а именно - литологическим характеристикам продуктивных $\left(\mathrm{B}_{9}\right.$ и $\left.Ю_{1}\right)$ зон с учётом их соотношения с подстилающими и перекрывающими горизонтами. Предполагается, что нефтематеринскими являются горизонты юрского и/или среднемелового возраста. Миграция нефти в вышележащие горизонты произошла уже после формирования трещиноватости.

Продуктивные интервалы приурочены к трещинным коллекторам. При этом один из них более однороден по составу и имеет существенно большую толщину, нежели второй, существенно более неоднородный по своей литологии. Несмотря на это, оба коллектора характеризуются сложным характером распределения трещин.

По степени влияния на извлекаемость нефти выделяется три типа трещин:

1) заполненные или частично заполненные. В зависимости от угла наклона они группируются в три подгруппы:

- с углом наклона 30-35 к длинной оси керна;

- вертикальные;

- субвертикальные.

Раскрытость трещин меняется в диапазоне 0,1-1,8 мм, а плотность - 18-36 1/м.

2) заполненные или частично заполненные кальцитом и кремнием. Они локализованы главным образом в интервале с большей толщиной. Для них характерна полифазная минерализация.

3) открытые. Выделены в обоих продуктивных интервалах. Трещины разнонаправлены. $\mathrm{Pa}$ скрытость меняется в интервале 0,1-0,2.

На рис. 4. показан результат моделирования системы разломов технологией «Ant Tracker» куба сейсмического атрибута хаоса и данных по керну. Зоны трещиноватости имеют линейные контуры и приурочены в основном к тектоническим нарушениям.

\section{Заключение}

Геометрические атрибуты дают количественные характеристики, которые могут быть использованы для прогнозирования плотности трещин. Кроме того, их можно использовать для решения задач в таких областях, как анализ геологического риска, геостатистика и др.

Когерентность и гибридный атрибут «Chaos» являются отличными инструментами для выделения геологических границ (разломы боковых стратиграфических контактов и т. д.). Когерентность позволяет дать экспрессную оценку больших наборов данных, обеспечивает количественную оценку наличия разломов и трещин, часто даёт возможность получения дополнительной стратиграфической информации, которую в противном случае трудно извлечь [22].

Объемная кривизна расширяет набор атрибутов, ранее ограниченных интерпретируемыми горизонтами, на весь интерпретируемый куб сейсмических данных.

Наиболее отрицательные и наиболее положительные основные кривизны представляются более однозначными характеристиками изо всех параметров кривизны, связанных с разломами и трещинами. 


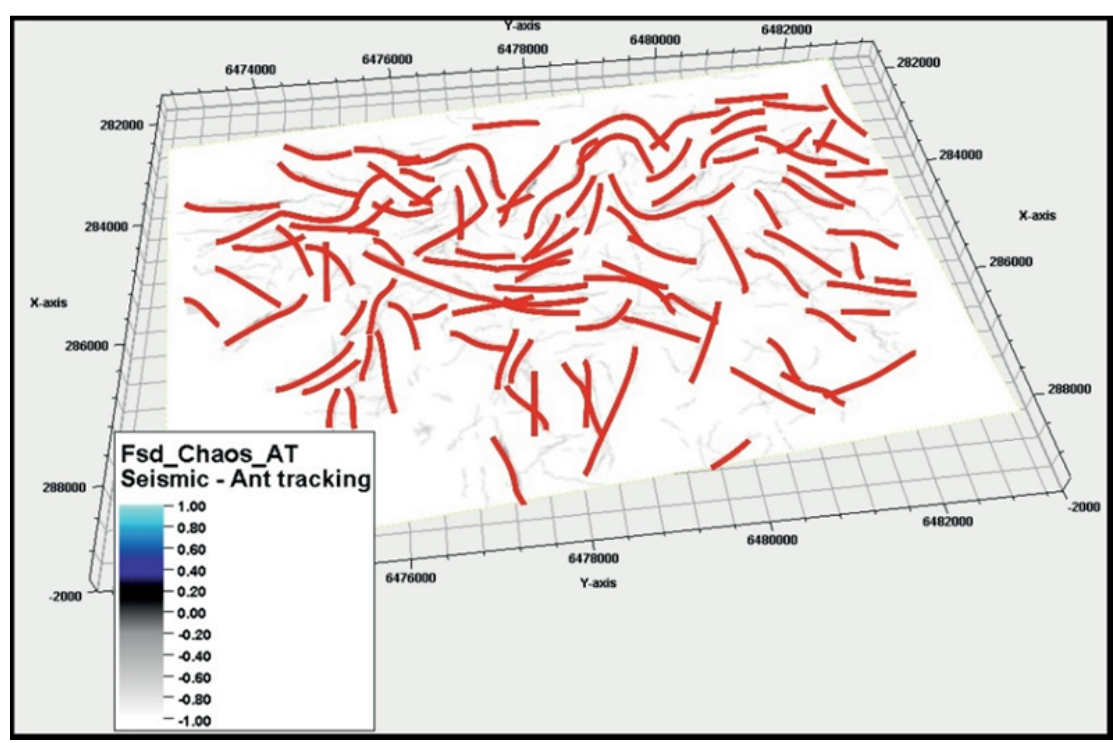

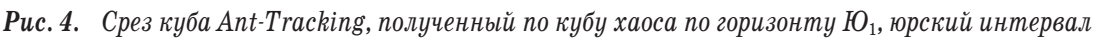

Fig. 4. Slice of the Ant-Tracking cube from chaos along the horizon $U_{1}$, Jurassic interval

Сейсмические атрибуты, такие как когерентность, кривизна и хаос, являются полезными прогностическими критериями локализации зон тектонической нарушенности. Оценить достоверность и перейти от качественных к количественным по-

\section{СПИСОК ЛИТЕРАТУРЫ}

1. Fracture characterization for carbonate reservoirs: a case study on oilfield in the eastern margin of the pre-Caspian basin / S.Q. Wang, L. Zhao, M. Luo, W.Q. Zhao, J.X. Li, C.G. Wang, M. Sun, L.D. Zhao, W.Q. Li, C.H. Li // Applied Ecology and Environmental Research. - 2018. - V. 16. - № 3. - P. 2885-2898.

2. Митюхина И.Ю., Спасский Б.А., Заключнов И.С. Изучение межскважинного пространства на основе многомерного анализа атрибутов сейсмических записей // Геофизика. - 2017. № 5. - C. 44-49.

3. Феоктистова 0.В. Определение классов потенциальной продуктивности сенонских отложений севера западной Сибири на основе корреляционных связей сейсмических атрибутов // Успехи современного естествознания. - 2018. - № 4. C. $160-166$.

4. Михайлова С.В. Анализ сейсмических атрибутов - комплексный подход при концептуальном моделировании // Рrонефть. Профессионально $о$ нефти. - 2018. - № 2. - С. 31-35.

5. Швецова М.Н. Прогноз коллекторских свойств на основе атрибутного анализа // Геология в развивающемся мире. Сборник научных трудов по материалам XI Международной научнопрактической конференции студентов, аспирантов и молодых ученых. В 3-х т.- Пермь: Пермский государственный национальный исследовательский университет, 2018. - С. 325-329.

6. Seismic attributes' application to evaluate the goru clastics of Indus basin, Pakistan / M.N. Tayyab, S. Asim, M.M. Siddiqui, M. Naeem, S.H. Solange, F.K. Babar // Arabian Journal of Geosciences. - 2017. - V. 10. - № 7. - C. 158-175.

7. Мендрий Я.В., Тяпкин Ю.К. Развитие технологии расчета когерентности на основе усовершенствованных моделей сейсмической записи // Геофизический журнал. -2012. - Т. 34. № 3. - C. 102-115.

8. Сейсмическая когерентность при флуктуациях временных задержек сигнала / Ю.К. Тяпкин, Я.В. Мендрий, А.Ю. Щего- казателям трещиноватости можно при наличии скважинной информации о направлении и интенсивности трещин на основе анализа поведения и распределения аномалий когерентности и кривизны в пространстве.

лихин, А.Н. Тяпкина // Геофизический журнал. - 2018. T. 40. - № 2. - C. 30-47.

9. Ромашев Е.А. Геометрические атрибуты геологических структур и их связь с трещиноватостью // Международная научнопрактическая конференция молодых исследователей им. Д.И. Менделеева. - Тюмень: Тюменский индустриальный университет, 2016. - С. 215-217.

10. Артемьев А.Е., Федорчук Р.А. Атрибуты кривизны и их использование для картирования дизъюнктивных нарушений // Геофизика. - 2006. - № 5. - С. 16-21.

11. Roberts A. Curvature attributes and their application to 3D interpreted horizons // First Break. - 2001. - V. 19. - № 2. - P. 85-100.

12. Коннов Д.А., Курмангалиев С.Б., Бражник А.Ю. Методика выявления разрывных нарушений на основании данных сейсморазведки при помощи различных методов атрибутивного анализа // Новейшие технологии освоения месторождений углеводородного сырья и обеспечение безопасности экосистем Каспийского шельфа: Материалы VIII Международной научно-практической конференции. - Астрахань: Астраханский государственный технический университет, 2017. - С. 76-79.

13. Применение «сухой смазки» для снижения риска прихватов при спуске хвостовиков под многостадийный гидроразрыв в условиях АВПД / Д.З. Махмутов, А.И. Якунов, С.С. Ложкин, А.В. Христенко, С.А. Черевко, М.А. Сыроегин // Бурение и нефть. - 2015. - № 12. - С. 42-43.

14. Разработка рецептуры руо unidril для бурения скважин с АВПД в ямало-ненецком автономном округе / М.С. Григорьев, Д.Н. Сидоров, Е.Н. Власов, А.В. Королев, П.Л. Рябцев // Бурение и нефть. -2017 . - № 3. - С. 46-49.

15. Валишин А.Я., Русских А.С. Анализ технологических решений первичного вскрытия нефтяных залежей в условиях АВПД // Современное состояние и пути развития науки XXI века: сборник статей по итогам Международной научнопрактической конференции. - Стерлитамак: Общество с огра- 
ниченной ответственностью «Агентство международных исследований» (Уфа), 2017. - С. 9-13.

16. Seismic prediction method of multiscale fractured reservoir / L.L. Wang, J.X. Wei, B.R. Di, P. Huang, F.H. Zhang // Applied Geophysics. - 2018. - V. 15. - № 2. - P. 240-252.

17. A Method for rock fracture network characterization based on topological structure / W. Li, W. Sun, T. Yan, Y. Li, Z. Ji, P. Tang // Tianranqi Gongye. - 2017. - V. 37. - № 6. - P. 22-27.

18. Сребродольская М.А., Федорова А.Ю. Скважинные сканирующие устройства: сравнительный анализ и интерпретация имиджей // Природные процессы в нефтегазовой отрасли. Сборник научных трудов Международной научно-практической конференции Студенческого отделения европейской ассоциации геоученых и инженеров. - Тюмень: Тюменский индустриальный университет, 2017. - С. 264-267.

19. Абетова С.А., Абетов А.Е. Интерпретация тектонических нарушений в объектах моделирования с использованием алгоритма ant-tracking в программном обеспечении petrel // Геология и охрана недр. - 2017. - № 4 (65). - С. 51-55.
20. Characterizing and modeling multi-scale natural fractures in the ordovician-silurian wufeng-longmaxi shale formation in south Sichuan basin / Q. Jun, X. Liang, G. Wang, C. Xian, C. Zhao, L. Wang // SPE/AAPG/SEG Unconventional Resources Technology Conference. - Austin, Texas, USA: Unconventional Resources Technology Conference, 2017. - P. 2626-2637

21. Septian L.S., Maulana A.I. Geological model of reservoir based on seismic attributes and ant tracking case study - f3 block, offshore Netherlands // $75^{\text {th }}$ European Association of Geoscientists and Engineers Conference and Exhibition. - London, United Kingdom, 2013. - Red Hook, NY: Curran,2014. - C. 6183-6185.

22. Степанов Д.Ю., Садыков Р.М. Прослеживание сейсмических волн и оценка когерентности - две стороны одной задачи // Геобайкал. 2018. URL: http://earthdoc.org/publication/publicationdetails/?publication=93693 (дата обращения 29.05.2019).

Поступила 18.06.2019 г.

\section{Информация об авторах}

Орехов А.Н., кандидат геолого-минералогических наук, доцент отделения геологии Инженерной школы природных ресурсов, Национальный исследовательский Томский политехнический университет.

Алани Мангуа M.M., аспирант отделения геологии Инженерной школы природных ресурсов, Национальный исследовательский Томский политехнический университет. 
UDC 551

\title{
INFORMATIVITY OF GEOMETRIC ATTRIBUTES FOR PREDICTING RESERVOIR FRACTURES ON THE EXAMPLE OF HYDROCARBONS DEPOSIT IN TOMSK REGION
}

\author{
Alexander N. Orekhov', \\ orekhovan@mail.tomsknet.ru \\ Amani Mangoua Marc Martial', \\ mangouam@yahoo.fr \\ 'National Research Tomsk Polytechnic University, \\ 30, Lenin Avenue, Tomsk, 634050, Russia.
}

In recent years, due to depletion of traditional hydrocarbon reservoirs, interest in, the permeability of which is mainly due to the degree of their fracturing collectors, has significantly increased. Prospects for mapping fractured zones are associated with seismic exploration. In essence, it is the only ground geophysical method that allows obtaining a detailed three-dimensional image of the geological environment. However, the possibilities of seismic exploration are limited by its resolution and the structure of the reservoir intervals.

Based on the results of our earlier comparative analysis of the latest techniques and technological methods for studying fractured cavernous reservoirs, the main methods for analyzing seismic data in the sequence in which they are presented in the surveys, were tested. They are ranked by breadth of use and proven effectiveness. By decreasing efficiency, methods for studying fracturing are as follows: 1. Azimuthal analysis of anisotropy with obtaining an effective model of azimuthal anisotropy; 2. Analysis of geometric attributes; 3. Special technologies of migration transformations (duplex migration, etc.); 4. Isolation of the field of scattered waves from a seismic record. Since the seismic survey carried out at the site is standard (not wide-azimuthal, not multi-azimuthal, not multiwave), only methods for analyzing geometric attributes were available to us to study fracturing from the list of the above methods. It should be noted that in this case the prediction of fracturing could be limited by the allocation of zones of fracturing (qualitative analysis).

The aim: study of the possibilities of seismic attribute for prediction and identification of tectonic disturbances and fracture enhancement zones.

Objects: rocks with a complex structure, intense cavernosity and fracturing reservoirs, due to which tectonic dislocations were formed in the sedimentary cover.

Methodology. Some volumetric seismic attributes, such as attributes of coherency and curvature (and its various variants), chaos were calculated. The results were visualized in the Schlumberger Petrel ${ }^{\circledR}$ software interface using available 3D CDP (Total Depth Point Method) seismic data to investigate potential structural and stratigraphic controls and highlight areas with fracture intensity within the study area. Similarly, surface attributes were taken on the horizon in order to create attribute maps and obtain a complete understanding of targets and features to highlight areas of intense crack development.

Results. Geometric attributes were analyzed to highlight fracture enhancement zones; seismic attribute calibration based on well data (core) was also considered.

\section{Key words:}

Cavern-pore type reservoirs, fracture type, fracture-porous-cavern type, seismic attributes, geometric attributes, coherency, curvature, chaos, Ant-Tracking.

\section{REFERENCES}

1. Wang S.Q., Zhao L., Luo M., Zhao W.Q., Li J.X., Wang C.G., Sun M., Zhao L.D., Li W.Q., Li C.H. Fracture characterization for carbonate reservoirs: a case study on oilfield in the eastern margin of the pre-Caspian basin. Applied Ecology and Environmental Research, 2018, vol. 16, no. 3, pp. 2885-2898.

2. Mityukhina I.Yu., Spassky B.A., Kronovna I.S. Study of the interwell space based on multidimensional analysis of the attributes of seismic records. Geophysics, 2017, no. 5, pp. 44-49. In Rus.

3. Feoktistova 0.V. Determining the classes of potential productivity of Senonian deposits in the north of Western Siberia based on the correlation of seismic attributes. Successes of modern science, 2018, no. 4, pp. 160-166. In Rus.

4. Mikhailov S.V. Conceptual model attribute analysis, petrophysical model, seismofacial model. Proneft. Professionally about oil, 2018, no. 2, pp. 31-35. In Rus.

5. Shvetsova M.N. Prognoz kollektorskikh svoystv na osnove atributnogo analiza [Prediction of reservoir properties based on attribute analysis]. Geologiya v razvivayushchemsya mire. Sbornik nauchnykh trudov po materialam XI Mezhdunarodnoy nauchnoprakticheskoy konferentsii studentov, aspirantov i molodykh uche$n y k h$ [Geology in the developing world. Collection of scientific papers on the materials of the XI International Scientific and Practical Conference of Students, Postgraduates and Young Scien- tists]. Perm, Perm State National Research University, 2018. pp. $325-329$.

6. Tayyab M.N., Asim S., Siddiqui M.M., Naeem M., Solange S.H., Babar F.K. Seismic attributes' application to evaluate the goru clastics of indus basin, pakistan. Arabian Journal of Geosciences, 2017, vol. 10, no. 7, pp. 158-175.

7. Mendry Ya.V., Tyapkin Yu.K. Development of coherence calculation technology based on improved seismic recording models. Geophysical journal, 2012, vol. 34, no. 3, pp. 102-115. In Rus.

8. Tyapkin Yu.K., Mendriy Ya.V., Shchegolikhin A.Yu., Tyapkina A.N. Seismic coherence in the presence of signal time-delay fluctuations. Geophysical journal, 2018, vol. 40, no. 2, pp. 30-47. In Rus.

9. Romashev E.A. Geometricheskie atributy geologicheskikh struktur i ikh svyaz s treshchinovatostyu [Geometric attributes of geological structures and their relationship with fracturing]. Mezhdunarodnaya nauchno-prakticheskaya konferentsiya molodykh issledovateley imeni D.I. Mendeleeva [International scientific-practical conference of young researchers. Mendeleev]. Tyumen, Tyumen Industrial University, 2016. pp. 215-217.

10. Artemyev A.E., Fedorchuk R.A. Curvature attributes and their use for mapping disjunctive disorders. Geophysics, 2006, no. 5, pp. 16-21. In Rus.

11. Roberts A. Curvature attributes and their application to 3 D interpreted horizons. First Break, 2001, vol. 19, no. 2, pp. 85-100. 
12. Konnov D.A., Kurmangaliyev S.B., Brazhnik A.Yu. Metodika vyyavleniya razryvnykh narusheniy na osnovanii dannykh seysmorazvedki pri pomoshchi razlichnykh metodov atributivnogo analiza [Methods of detecting faults based on seismic data using various methods of attributive analysis]. Noveyshie tekhnologii osvoeniya mestorozhdeniy uglevodorodnogo syrya $i$ obespechenie bezopasnosti ekosistem Kaspiyskogo shelfa. Materialy VIII Mezhdunarodnoy nauchno-prakticheskoy konferentsii [Innovative technologies for development of hydrocarbon deposits and ensuring the safety of the ecosystems of the Caspian shelf. Materials of the VIII International Scientific and Practical Conference]. Astrakhan, Astrakhan State Technical University, 2017. pp. $76-79$.

13. Makhmutov D.Z., Yakunov A.I., Lozhkin S.S., Khristenko A.V., Cherevko S.A., Syroegin M.A. Use of «dry lubrication» to reduce the risk of sticking during the descent of the shanks under multistage hydraulic fracturing in conditions of AHPP. Drilling and oil, 2015, no. 12, pp. 42-43. In Rus.

14. Grigoriev M.S., Sidorov D.N., Vlasov E.N., Korolev A.V., Ryabtsev P.L. Development of the recipe for ruo unidril for drilling wells with automatic gearing in the Yamalo-Nenets Autonomous District. Drilling and oil, 2017, no. 3, pp. 46-49. In Rus.

15. Valishin A.Ya., Russkikh A.S. Analiz tekhnologicheskikh resheniy pervichnogo vskrytiya neftyanykh zalezhey $\mathrm{v}$ usloviyakh AVPD [Analysis of technological solutions for the initial opening of oil deposits in the conditions of AHPP]. Sovremennoe sostoyanie i puti razvitiya nauki XXI veka. Sbornik statey po itogam Mezhdunarodnoy nauchno-prakticheskoy konferentsii [Current state and ways of development of science of the XXI century. Collection of articles on the results of the International Scientific and Practical Conference]. Sterlitamak, Agency for International Studies Limited Liability Company (Ufa), 2017. pp. 9-13.

16. Wang L.L., Wei J.X., Di B.R., Huang P., Zhang F.H. Seismic prediction method of multiscale fractured reservoir. Applied Geophysics, 2018, vol. 15, no. 2, pp. 240-252.
17. Li W., Sun W., Yan T., Li Y., Ji Z., Tang P. A Method for rock fracture network characterization based on topological structure. Tianranqi Gongye, 2017, vol. 37, no. 6, pp. 22-27.

18. Srebrodolskaya M.A., Fedorova A.Y. Skvazhinnye skaniruyushchie ustroystva: sravnitelny analiz i interpretatsiya imidzhey [Wells Scanning Devices: Comparative Analysis and Image Interpretation]. Prirodnye protsessy v neftegazovoy otrasli. Sbornik nauchnykh trudov Mezhdunarodnoy nauchno-prakticheskoy konferentsii Studencheskogootdeleniya evropeyskoy assotsiatsii geouchenykh i inzhenerov [Natural Processes in the Oil and Gas Industry. Collection of scientific papers of the International Scientific and Practical Conference of the Student Branch of the European Association of Geoscientists and Engineers]. Tyumen, Tyumen Industrial University, 2017. pp. 264-267.

19. Abetova S.A., Abetov A.E. Interpretation of tectonic disturbances in modeling objects using the ant-tracking algorithm in petrel software. Geology and protection of mineral resources, 2017, no. 4 (65), pp. 51-55. In Rus.

20. Jun Q., Liang X., Wang G., Xian C., Zhao C., Wang L. Characterizing and modeling multi-scale natural fractures in the ordovician-silurian wufeng-longmaxi shale formation in south sichuan basin. SPE/AAPG/SEG Unconventional Resources Technology Conference. Austin, Texas, USA, Unconventional Resources Technology Conference, 2017. pp. 2626-2637

21. Septian L.S., Maulana A.I. Geological model of reservoir based on seismic attributes and ant tracking case study - $\mathrm{f} 3$ block, offshore Netherlands. 75th European Association of Geoscientists and Engineers Conference and Exhibition. London, United Kingdom, 2013. Red Hook, NY, Curran, 2014. pp. 6183-6185.

22. Stepanov D.Yu., Sadykov R.M. Seismic Wave Tracking and Coherence Estimation Are Two Sides of the One Task. Geobaikal, 2018. Available at: http://earthdoc.org/publication/publicationdetails/?publication=93693 (accessed 29 May 2019).

Received: 18 June 2019.

\section{Information about the authors}

Alexander N. Orekhov, Cand. Sc., associate professor, National Research Tomsk Polytechnic University.

Amani Mangoua Marc Martial, postgraduate student, National Research Tomsk Polytechnic University. 